\title{
Accidental ingestion of a toothbrush
}

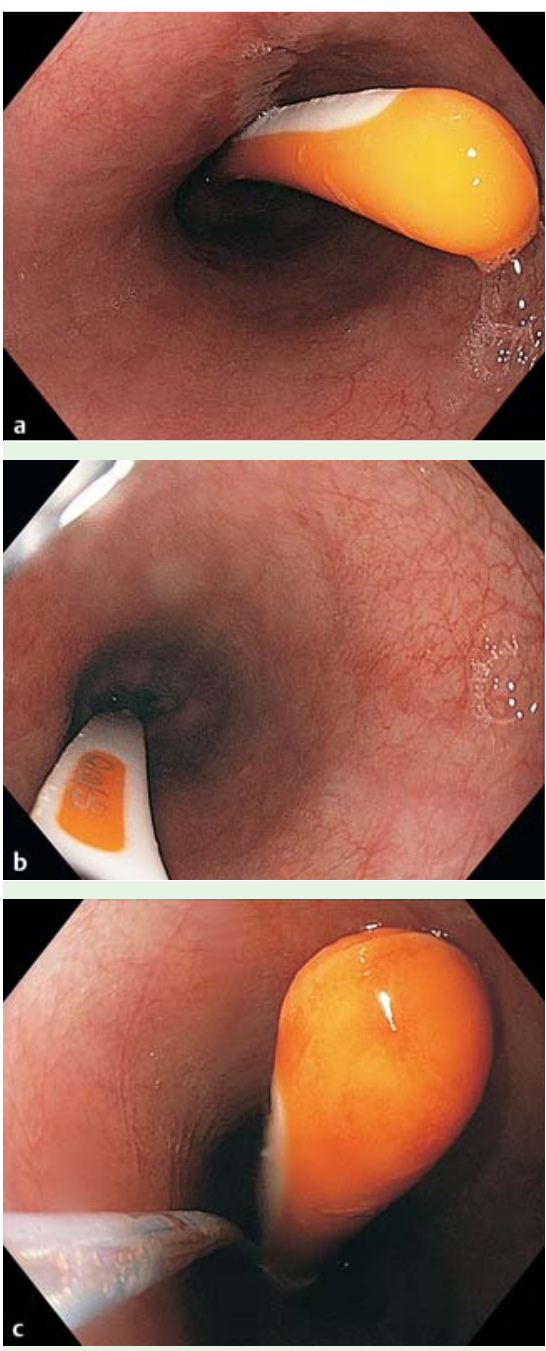

Fig. 1 Endoscopic views in an adult Nigerian man who had accidentally swallowed his toothbrush showing: a the distal end of the toothbrush, which was located within the esophagus after becoming impacted at the gastroesophageal junction; b the toothbrush in the esophagus (anterior view); c the toothbrush being held with the grasping forceps prior to its removal.

Foreign bodies of the gastrointestinal tract are common; they can be ingested or inserted accidentally or intentionally [1], with $80 \%$ of cases occurring in children between the ages of 6 months and 3 years [2]. In adults, ingestion of foreign bodies often occurs accidentally [1]; however, psychiatric patients, people who are incarcerated, malingerers, and those with an altered sensorium may sometimes ingest foreign bodies intentionally [3]. Here we report the case of an adult Nigerian man who accidentally ingested his toothbrush.

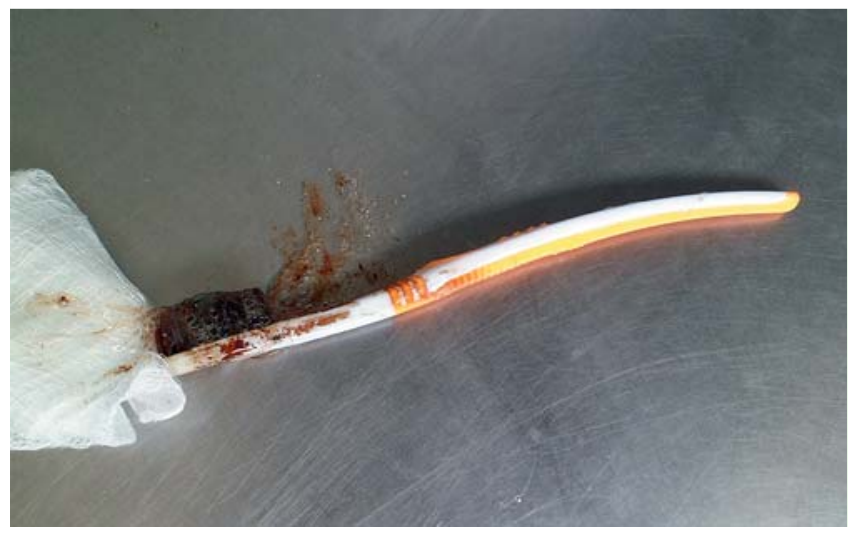

Fig. 2 The toothbrush after its removal from the esophagus.

A 28 year-old man presented after inadvertently swallowing an adult-sized toothbrush while brushing his mouth. He had no other previous medical history and no background of psychiatric illness. General and systemic examinations were unremarkable and his vital signs were normal. Chest and abdominal radiographs done before referral to our department were said to have located the foreign body in the stomach. Upper gastrointestinal endoscopy performed with an Olympus gastroscope (GIF-HQ190), however, showed the toothbrush to be in the esophagus ( $\bullet$ Fig. 1 a,b) and grasping forceps (FG-301Q) were used to remove it ( $\bullet$ Fig. 1 c and $\bullet$ Fig. 2 ).

The majority of ingested foreign bodies are able to pass through the gastrointestinal tract without causing significant harm [4]. However, a patient may become symptomatic or develop complications when a foreign body fails to pass spontaneously. Our patient was asymptomatic and tolerating oral intake on presentation.

The toothbrush in this case became impacted at the gastroesophageal junction (GEJ), which is one of the four areas of physiologic narrowing in the esophagus. This finding is similar to other cases previously reported [5-8]. The poor localization of the toothbrush on radiographs may be explained by the non-radiopaque nature of the object. However, in some series false-negative and false-positive rates for radiography of up to $47 \%$ and $20 \%$ respectively have been reported [9]. Although up to $90 \%$ of foreign bodies in the gastrointestinal tract will be passed spontaneously, objects located in the esophagus should be removed as soon as possible [10].

\section{Endoscopy_UCTN_Code_CCL_1AB_2AF}

Competing interests: None

\section{Adegboyega Akere', Oludolapo O. Afuwape ${ }^{2}$}

${ }^{1}$ Department of Medicine, University College Hospital, Ibadan, Nigeria

2 Department of Surgery, University College Hospital, Ibadan, Nigeria

\section{References}

1 Pfau PR, Ginsberg GG. Foreign Bodies and Bezoars. In: Feldman M, Friedman LS, Sleisenger MH. Sleisenger \& Fordtran's Gastrointestinal and Liver Disease, Pathophysiology/Diagnosis/Management. Volume 1. 7th edn. Philadelphia: Saunders; 2002: 386-398

2 Webb WA. Management of foreign bodies of the upper gastrointestinal tract. Gastroenterology 1988; 94: 204-216

3 Chalk SG, Faucer H. Foreign bodies in the stomach. Arch Surg 1928; 16: 494-500

4 Schwartz GF, Polsky HS. Ingested foreign bodies of the gastrointestinal tract. Am Surg 1976; 42: 236-238

5 Mosca S, Manes G, Martino $R$ et al. Endoscopic management of foreign bodies in the upper gastrointestinal tract: report on a series of 414 adult patients. Endoscopy 2001; 33: $692-696$

6 Li ZS, Sun ZX, Zou DW et al. Endoscopic management of foreign bodies in the upper-GI tract: experience with 1088 cases in China. Gastrointest Endosc 2006; 64: 485-492

7 Park JH, Park CH, Lee WS et al. Review of 209 cases of foreign bodies in the upper gastrointestinal tract and clinical factors for successful endoscopic removal. Korean J Gastroenterol 2004; 43: 226-233

8 Khurana AK, Saraya A, Jain $N$ et al. Management of foreign bodies of the upper gastrointestinal tract. Trop Gastroenterol 1998; 19: $32-33$ 
9 Herranz-Gonzalez J, Martinez-Vidal J, GarciaSarandeses A et al. Oesophageal foreign bodies in adults. Otolaryngol Head Neck Surg 1991; 105: 649-654

10 Velitchkov NG, Grigorov GI, Losanoff JE et al Ingested foreign bodies of the gastrointestinal tract: Retrospective analysis of 542 cases. World J Surg 1996; 20: 1001 - 1005
Bibliography

DOI http://dx.doi.org/

10.1055/s-0033-1359128

Endoscopy 2014; 46: E38-E39

(c) Georg Thieme Verlag KG

Stuttgart · New York

ISSN 0013-726X
Corresponding author

Adegboyega Akere, MD

Dept. of Medicine, University of Ibadan P.O. Box 28829

Agodi, Ibadan

Oyo State

Nigeria

Fax: +234-8-033257211

adeakere@yahoo.co.uk 